\title{
IFMuC: un proyecto universitario para la recuperación del Patrimonio Musical de Catalunya
}

\author{
IFMuC: A University Project for the Recovery of \\ Musical Heritage of Catalonia
}

\author{
Josep Maria Gregori i Cifré \\ Universidad Autónoma de Barcelona \\ JosepMaria.Gregori@uab.cat
}

\section{RESUMEN}

Este artículo se centra en reflejar la trayectoria de la recuperación del patrimonio musical de Catalunya, estudiando en primer los antecedentes desde el siglo XIX hasta la creación, ya en el siglo XX, del Centre de Documentació Musical (CDM) y del Institut de Documentació i d'Investigació Musicològiques Josep Ricart i Matas (IDIM), ambos organismos promovidos desde la Universidad Autónoma de Barcelona (UAB). Ello sirve para comprender la necesidad y motivación del proyecto IFMuC (Inventari dels Fons Musicals de Catalunya), creado asimismo en el seno de la UAB con el objetivo principal de crear una base de datos digital que ponga a disposición de la comunidad musical un repertorio inédito que aporte información y acceso a las principales fuentes musicales de Catalunya con un cuádruple beneficio: científico, artístico, social y educativo.

Palabras clave: Recuperación, catalogación, patrimonio musical, Catalunya, antecedentes, IFMuC, base de datos, universidad.

\begin{abstract}
This article focuses on reflecting the trajectory of the recovery of Catalan musical heritage, first studying the antecedents from the 19th century to the creation, in the 20th century, of the Center for Musical Documentation (CDM) and the Institut de Documentació $\mathrm{i}$ D'Investigació Musicològiques Josep Ricart i Matas (IDIM), both organizations promoted from the Autonomous University of Barcelona (UAB). This serves to understand the need and motivation of the IFMuC project (Inventari dels Fons Musicals de Catalunya), also created within the $\mathrm{UAB}$ with the main objective of creating a digital database that puts at the disposal of the musical community an unpublished repertoire. That provides information and access to the main musical sources of Catalonia with a fourfold benefit: scientific, artistic, social and educational.
\end{abstract}




\section{IFMUC: UN PROYECTO UNIVERSITARIO PARA LA RECUPERACIÓN DEL}

Patrimonio Musical de Catalunya

Key words: Recovery, Cataloging, Musical Heritage, Catalonia, History, IFMuC, Database, University.

Gregori i Ciffré, J. M. (2016). IFMuC: un proyecto universitario para la recuperación del Patrimonio Musical de Catalunya. Cuadernos de Investigación Musical, 1, 12-26.

doi: http://dx.doi.org/10.18239/invesmusic_2016.01.1306

\section{LOS INICIOS DE LA RECUPERACIÓN DEL PATRIMONIO MUSICAL}

Catalunya se sumó pronto a la mirada hacia el pasado musical emprendida por los países centroeuropeos durante la segunda mitad del siglo XIX, gracias al nacimiento de la musicología en las universidades alemanas. Las primeras iniciativas se centraron en la identificación y el estudio del canto popular -a través de la búsqueda de materiales procedentes de la tradición oral-, así como en los primeros estudios y ediciones de repertorio musical conservado en archivos y bibliotecas, todos ellos imprescindibles para la restitución de la historia musical de nuestro país.

Cuando Felip Pedrell (1841-1922) afirmaba en 1894 "la antigua música española, desgraciadamente, muy poco estimada por la senzilla razón de que no es conocida, nos reserva grandes sorpresas" (Pedrell, 1894: XLVI), además de mostrar su conciencia del desconocimiento general que se tenía, a finales del siglo XIX, del repertorio de los antiguos maestros de capilla y organistas, manifestaba su férreo compromiso en pro de la recuperación del patrimonio musical hispánico. Así lo puso de manifiesto en sus ensayos «Los músicos españoles antiguos y modernos en sus libros o escritos sobre la música»" previos a la edición de su ideario Por nuestra música (1891), Pedrell, como Baltasar Saldoni fue el primer musicólogo que comprendió la necesidad de elaborar un diccionario biográfico de ámbito peninsular (1868-1881 y 1897). Su anhelo por la recuperación del repertorio le condujo a Pedrell a publicar la antología Hispanice Schola Musica Sacra (18941897) ${ }^{2}$, las Opera Omnia de Tomás Luis de Victoria (1902-1913) y el Cancionero Musical Popular Español (1918-1922).

El ideario pedrelliano tomó raíces en sus discípulos -sobretodo, Higini Anglès- e influyó en una institución bandera en el país desde finales del siglo XIX: el Orfeó Català, fundado por Lluís Millet y Amadeu Vices, en 1891. Esta institución contribuyó de forma decisiva en la recuperación del repertorio musical catalán mediante la publicación de la Revista Musical Catalana (1904-1936) ${ }^{3}$ y el inicio de la Obra del Cançoner Popular de Catalunya en

\footnotetext{
1 Pliegos sueltos de la revista La Ilustración Musical Hispano-Americana (Barcelona, 1888-1896). Solamente se publicaron las primeras 128 páginas, 1888.

${ }^{2}$ Los 8 volúmenes, publicados entre 1894 y 1897, contienen música de A. de Cabezón, R. de Ceballos. C. de Morales, F. Guerrero, J. Ginés Pérez, T. de Santa Maria, T. L. de Victoria.

${ }^{3}$ Donde publicó la serie Músichs Vells de la terra, entre 1904 y 1910.
} 
1922, gracias a la fundación Concepció Rabell i Civils, creada por el mecenas Rafael Patxot i Jubert. Aquella iniciativa se convirtió en el punto de partida de la recuperación del patrimonio de la canción popular y tradicional en Catalunya ${ }^{4}$.

Las dos primeras décadas del siglo XX ofrecen destacadas actuaciones institucionales en torno al patrimonio. Desde la Mancomunitat de Catalunya, y con el concurso de personalidades como Enric Prat de la Riba, Joan Pijoan y Josep Puig i Cadafalch, se fundaron tres instituciones con la voluntad explícita de contribuir a la preservación del patrimonio: la Junta de Museus de Barcelona (1906), el Institut d'Estudis Catalans (1907) y la Biblioteca de Catalunya (1911).

La Junta de Museus - depositaria de la importante biblioteca musical comprada a Joan Carreras i Dagas- encargó la catalogación de su fondo a Felip Pedrell, quién completó su cometido con la edición de los dos volúmenes del catálogo en 1908-19095. Cuando en 1917 se creaba la «Secció de Música» de la Biblioteca de Catalunya, el cargo de conservador fue ofrecido a Pedrell, quien lo declinó a favor de su discípulo Higini Anglès (1888-1969). La presencia de Anglès dio un impulso determinante a la conciencia de la recuperación del patrimonio gracias a sus destacadas contribuciones en esta labor, como las primeras ediciones de las obras de Mateu Fletxa el Vell, Joan Brudieu, Joan Pujol, Joan Baptista Cabanilles, junto a pioneros estudios históricos que a lo largo de los años siguen manteniendo su carácter fundamental, como la imprescindible La música a Catalunya fins al s. XIII (1935).

La Sección de Música de la Biblioteca de Catalunya recibió un nuevo impulso gracias a la incorporación de la bibliotecaria Joana Crespí en 1983, la cual llevó a cabo una intensa labor de ordenación y catalogación de los fondos musicales de la institución. Su impulso renovador en la gestión del patrimonio escrito y sonoro de la «Secció de Música» fue asumido, desde 2005, por Maria Rosa Montalt. La Biblioteca de Catalunya, junto a los tesoros patrimoniales de los fondos históricos, cuenta en la actualidad con més de cien fondos personales de compositores, intérpretes y musicólogos, siendo el principal centro catalizador del patrimonio musical en Catalunya (Montalt, 2013: 626-631).

En 1943 se creaba en Barcelona el Instituto Español de Musicología del CSIC, liderada por el mismo H. Anglès, quién contó con un excelente equipo de colaboradores ${ }^{6}$. En 1946 creó la revista Anuario Musical e inició la publicación de las obras de los maestros de la tradición hispánica del Renacimiento7. El Instituto Español de Musicología fue dirigido posteriormente per Miquel Querol (1969 a 1982) -iniciador de los estudios sobre el barroco musical hispánico-, Josep Maria Llorens (1982 a 1988), José Vicente González

\footnotetext{
4 La colección de materiales superaba los 40.000 documentos en 1936. Entre sus colaboradores cabe mencionar a Joan Amades, Higini Anglès, Josep Barberà, Pere Bohigas, Palmira Jacquetti, Joan Llongueras, Francesc Pujol, Joan Puntí, Joan Sala, Baltasar Samper y Joan Tomàs.

${ }^{5} \mathrm{El}$ encargo había previsto la redacción de un «catàleg monumental il lustrat, amb comentaris crítics i il·lustracions musicals.» Cf. Pedrell, F. (1908). Catàlech de la Biblioteca Musical de la Diputació de Barcelona (vol. I). Barcelona: Diputación Provincial, pp. 9-15.

${ }^{6}$ Cabe destacar, entre los primeros, a Miquel Querol, Josep Romeu, Francesc Baldelló, Marius Schneider, Santiago Kastner, Joan Tomàs, Emili Pujol, José Antonio Donostia y Josep Subirà.

${ }^{7}$ Como el Cancionero Musical de Palacio y las Opera Omnia de C. de Morales, F. Guerrero y T. L. de Victoria, así como los estudios y ediciones de los vihuelistas Luis de Narváez y Alonso de Mudarra.
} 


\section{IFMUC: UN PROYECTO UNIVERSITARIO PARA LA RECUPERACIÓN DEL Patrimonio Musical de Catalunya}

Valle (1988 a 2001) y Antonio Ezquerro (2001), y cuenta en la actualidad con la presencia de los investigadores Mariano Lambea, María Gembero y Emili Ros-Fàbregas. Desde 1991 acoge en su seno la «Redacción Central de RISM-España».

En esta breve trayectoria sobre el patrimonio cabe mencionar el Museu de la Música -inaugurado en 1946 bajo la dirección de Josep Ricart i Matas (1893-1978)-, organismo imprescindible en lo que se refiere a la preservación y estudio del patrimonio organológico. Manuel Valls, sucesor de Josep Ricart, trasladó el Museu del ático del Conservatorio Superior de Música al antiguo palacete del Baró de Quadras del ensanche barcelonés. En 1983 se hizo cargo del mismo Romà Escalas, quién creó un equipo de expertos profesionales, y publicó el Catàleg del Museu de la Música, en 1991. En el 2007 se trasladó a L'Auditori de Barcelona, con un nuevo discuso museográfico y una renovada presentación de sus colecciones de instrumentos y documentos musicales. El museo cuenta con más de una veintena de fondos musicales, personales y de instituciones.

Dentro del marco de esta breve panorámica, merece una mención especial el monasterio de Montserrat, con la obra restauradora del P. Joan Baptista Guzmán (18461909), que había publicado en Madrid, en 1888, las obras de Joan Baptista Comes. El impulso fundamental se reinició en 1930 de la mano del P. David Pujol (1894-1979), con la serie Mestres de l'Escolania de Montserrat, continuada después por los P. Gregori Estrada, Ireneu Segarra y Daniel Codina. Esta labor editora ha venido acompañada de la grabación de una parte significativa de este repertorio, con lo que se dio inicio a una nueva vía de difusión del patrimonio musical catalán.

En 1983 la Generalitat de Catalunya creó el Centre de Documentació Musical de Catalunya, instalado en el Jardí dels Tarongers, antigua residencia del mecenas Josep Bartomeu i Granell. El centro acogió fondos musicales de E. Granados, E. Morera, los hermanos Lamote de Grignon, entre otros. A raíz de su clausura, los fondos de este centro pasaron a la Biblioteca Nacional de Catalunya en 2005.

Entre los años 1984 y 1991, el equipo formado por María Ester-Sala y Josep M. Vilar, ambos formados en la Universitat Autònoma de Barcelona, llevó a cabo una encomiable labor de divulgación y sensibilización sobre el estado de los fondos musicales de Catalunya, de la que dejaron constancia en diversas publicaciones (Ester-Sala y Vilar: 1987; Ester-Sala y Vilar: 1989; Ester Sala y Vilar: 1992).

\section{ANTECEDENTES DE IFMUC}

2.1. El Centre de Documentació Musical (CDM) De la Universitat Autònoma de BARCELONA (1973-1979)

El CDM de la UAB vio la luz gracias a la iniciativa del profesor Francesc Bonastre, quien con la colaboración del profesor Antonio Martín Moreno ${ }^{8}$ y los estudiantes que cursábamos los estudios universitarios del Área de Música, propició la formación de un

\footnotetext{
8 Profesor del Departament d'Art de la UAB entre 1973 y 1978. 
equipo de investigación orientado hacia la catalogación y el estudio de los fondos de manuscritos musicales catalanes. En el curso de los años 1975-1978, formamos parte de aquel equipo de investigadores incipientes, Joan Bagüés, Josep M. Vives y quien escribe estas palabras, entre otros.

La primera labor investigadora de aquel equipo fue acometer, entre 1975 y 1981, la catalogación y microfilmación del fondo musical de la catedral de Tarragona. Aquella laboriosa empresa, llevada a cabo gracias a la perseverancia de continuados viajes semanales, resultó ser para aquellos jóvenes aprendices de musicólogos, el atanor en el que se coció, a fuego lento, la vocación musicológica unida del deseo de trabajar en la recuperación del patrimonio musical. Durante los cursos 1975-76 y 1976-77, éramos un pequeño grupo de estudiantes ilusionados que disfrutábamos del privilegio de contemplar, admirados y maravillados, los tesoros musicales de la catedral tarraconense que yacían desde siglos en un pétreo sueño. Allí pudimos descubrir, directamente, desde las propias fuentes los diferentes aspectos lingüísticos y estéticos del barroco musical. Aquella especie de bautismo musicológico fructificó en trabajos aplicados a la recuperación del patrimonio musical tarraconense ${ }^{9}$ y en la apertura de nuevas líneas de investigación en el terreno de la metodología de catalogación de manuscritos musicales ${ }^{10}$.

Las intervenciones que llevo a cabo el equipo del CDM de la UAB entre 1976 y 1980 se centraron en los fondos musicales de Santa Maria del Pi (Barcelona), Santa Maria de la Geltrú, Sant Esteve d'Olot, Santa Pau dels Arcs y Sant Joan de les Abadesses.

\subsection{El Institut de Documentació I D’InVESTiGació MusicològIQUes JoseP RicART I MATAS (1980)}

La propuesta de creación del Institut de Documentació i d'Investigació Musicològiques Josep Ricart i Matas (IDIM) fue aprobada según la orden ministerial del 6 de junio de 1979. El IDIM se inauguró el 15 de mayo de 1980 (Bonastre, 1993: 85-91). El IDIM recogió la labor realizada por el CDM y asumió con un carisma más confirmativo las funciones que la LRU atribuía a los institutos universitarios, es decir, las propias de un centro profesional de investigación.

La puesta en marcha del IDIM supuso, respecto a la labor realizada en los archivos, la obertura de una época de trabajo paciente y silencioso, sin resultados espectaculares. Una vez terminada la microfilmación del fondo de manuscritos musicales de la catedral de Tarragona, en 1981, se procedió a iniciar el fichaje de uno de los fondos de mayor envergadura y de los de mayor interés para el estudio del barroco musical en Catalunya, me

\footnotetext{
$9 \mathrm{Vid}$. una de las primeras investigaciones con las que Francesc Bonastre inauguraba sus contribuciones al estudio del barroco (Bonastre, 1976-77) y mi tesis de licenciatura centrada en el estudio y la transcripción de la obra de un maestro de la catedral del s. XVIII (Gregori i Cifré, 1977).

${ }^{10}$ La metodología descriptiva del primer catálogo del fondo de la catedral de Tarragona (1977) sirvió de modelo a las ediciones de los primeros catálogos de manuscritos musicales que se publicaron en España a partir de 1980.
} 


\section{IFMUC: UN PROYECTO UNIVERSITARIO PARA LA RECUPERACIÓN DEL Patrimonio Musical de Catalunya}

refiero al fondo de Canet de Mar, un fondo con mas de dos mil manuscritos, cuya labor de fichaje y microfilmación de este fondo se llevó culminó en 1982.

Entre 1983 y 1984 se procedió, mediante un convenio institucional entre el IDIM y la Biblioteca de Catalunya y gracias a un proyecto de investigación subvencionado, a la primera fase de catalogación del fondo musical Joan Careras y Dagas de la Biblioteca de Catalunya.

Mediante dos proyectos subvencionados por la CIRIT (Generalitat de Catalunya) se realizó en 1986 el inicio de la catalogación del fondo de Santa Maria de Vilafranca del Penedès, situado en el Museu del Vi (Vinseum), mientras en 1987 se procedió a trabajar, en una primera fase, en la colección de manuscritos musicales de la catedral de Tortosa (Gregori, 1994: 863-865).

La herencia del CDM y IDIM, en lo que atañe a la labor de catalogación, estudio y difusión de los fondos musicales catalanes y de su repertorio, ha sido asumida desde el curso 2001-2002 por el proyecto IFMuC de la UAB.

\section{El PROYECTO IFMuC DE LA UNIVERSITAT AUTÒNOMA DE BARCELONA}

\section{1. MOTIVACIONES Y PROCESO}

Catalunya es uno de los pocos países europeos que aun desconoce la riqueza de su patrimonio musical, en lo que atañe al repertorio compositivo de sus maestros de capilla, organistas y músicos, que ser conserva olvidado en numerosos archivos, principalmente eclesiásticos. Sin embargo, esta riqueza que aun permanece desconocida ha podido sobrevivir la numerosas contiendas bélicas que han acechado a nuestro país durante los últimos siglos. Solamente cabe imaginar, por unos instantes, cuales serían los titulares de la prensa si se anunciara el descubrimiento de miles de obras desconocidas de literatos de primera fila o de centenares de pinturas y esculturas de renombrados artistas. Esto es, precisamente, lo que sucede con el repertorio compositivo de los músicos catalanes de los siglos pretéritos.

Desde la edición, en 1908, del Catàlech de la Biblioteca Musical de la Diputació de Barcelona (actual Biblioteca Nacional de Catalunya) de Felip Pedrell, hasta la edición en el año 2007 del primer volumen de la serie Inventaris dels Fons musicals de Catalunya dedicado al catálogo del fondo musical de la catedral-basílica de Terrassa (TerC), hemos necesiatdo prácticamente cien años para poner en marcha un proyecto de país pensando en la recuperación sistemática de la riqueza musical conservada en los archivos catalanes.

Esta es, pues, una de las grandes lagunas musicológicas, y humanísticas, de nuestro país: volver a hilvanar el largo proceso de recuperación de la memoria musical de nuestros antepasados. Una forma de hacerlo desde la universidad, es transmitiendo a los estudiantes la conciencia de esta urgencia, comunicándoles, a su vez, la ilusión de participar en un proyecto centrado en dicha recuperación, puesto que, en pleno siglo XXI, buena parte del patrimonio musical de Catalunya permanece aun desatendido, olvidado e ignorado e los 
depósitos documentales y en las zonas de reserva de numerosos archivos y bibliotecas sin que se preste atención al valor artístico que contienen.

Por todo ello, a partir del curso académico 2001-2002, decidimos iniciar, en el seno del Departament d'Art i Musicologia de la Universitat Autònoma de Barcelona, una nueva linea de investigación con la prioridad inmediata de trabajar en la recuperación de los fondos de manuscritos musicales que constituyen el patrimonio musical de Catalunya, mediante la confección y edición, en su origen impresa, de sus respectivos inventarios catalográficos. Actualmente, después de doze cursos académicos, y gracias a las prácticas integradas de las asignaturas de Patrimoni Musical y Practicum d'Arxivística, impartidas en la universidad y, sobretodo, en los propios archivos que custodian los fondos, podemos decir, a la luz de los resultados publicados en los últimos años, que hemos encauzado esta labor con entusiasmo y voluntad de servicio a nuestro país, así como a la comunidad científica y artística internacional. ${ }^{11}$

En fecha de hoy, la Universitat Autònoma de Barcelona mantiene Convenios de Prácticas de Patrimonio Musical con los archivos eclesiásticos de las catedrales de Girona y Lleida, con las parroquias de Castelló d'Empúries, Sant Pere de Reus, Santa Maria del Pi de Barcelona, Sant Pere i Sant Pau de Canet de Mar, Arxiu Diocesà de Solsona, Arxiu Diocesà de Girona, Museu-Arxiu de Santa Maria de Mataró, Museu del Vi de Vilafranca del Penedès, los archivos de Igualada, Ripoll y Tàrrega de la red de Arxius Històrics Comarcals de la Generalitat de Catalunya, la Biblioteca del Seminari Episcopal de Barcelona y el Centre de Documentació i Gestió Documental de l'Orfeó Català - Palau de la Música Catalana.

Entre 2001 y 2016 hemos censado más de 200 fondos de manuscritos con obras desconocidas de compositores catalanes y ya empezamos a conocer un pequeño tanto por ciento de la riqueza musical que permanece en los fondos históricos de nuestras catedrales, basílicas e iglesias parroquiales. De los fondos ubicados en archivos públicos, eclesiásticos y privados, 15 han sido catalogados, con un índice de cerca de mil compositores y más de diez mil registros catalográficos.

Entre 2007 y 2016 hemos completado la confección de los inventarios-catálogos de los fondos musicales:

\footnotetext{
11 Para la descripción de este proceso se pueden consultar los siguientes artículos: Gregori i Cifré, J. M. (2008). "El inventario de los fondos musicales eclesiásticos de Catalunya, un proyecto en marcha desde la Universitat Autónoma de Barcelona”. Memoria Ecclesiae, XXXI, pp. 483-497. Gregori i Cifré, J. M. (2013). "Els Inventaris dels Fons Musicals de Catalunya, el projecte de la UAB per a la recuperació del patrimoni musical", $2 n$ Congrés Internacional de Música. Barcelona: Consell Català de la Música, pp. 621-625. Gregori i Cifré, J. M. (2014). "Fondos Musicales en Catalunya: el proyecto IFMuC de la Universitat Autònoma de Barcelona para la recuperación del patrimonio musical catalán”, en M. Nagore y V. Sánchez (eds.). Allegro cum laude. Estudios musicológicos en homenaje a Emilio Casares. Madrid: Instituto Complutense de Ciencias Musicales, pp. 127-134. Gregori i Cifré, J. M. (2015).“Catalonia project report”. Early Music, 43, 367-368. Gregori i Cifré, J. M. (2015). "El nou web al servei del patrimoni musical de Catalunya http://ifmuc.uab.cat". Revista Catalana de Musicologia, VIII, pp. 23-35. Gregori i Cifré, J. M. (2016). "El Cens IFMuC dels fons musicals de Catalunya". Lligall, 38, pp. 134-168.
} 


\section{IFMUC: UN PROYECTO UNIVERSITARIO PARA LA RECUPERACIÓN DEL}

Patrimonio Musical de Catalunya

1. Catedral-basílica del Sant Esperit de Terrassa (TerC), con un cómputo de 672 manuscritos de autor, 291 anónimos, 16 libros corales y 9 impresos. Repertorio de los siglos XVIII, XIX y XX.

2. Iglesia parroquial de Sant Pere i Sant Pau de Canet de Mar (CMar), con 1.196 manuscritos de autor y 923 anónimos. Notable presencia de repertorio de los siglos XVII y XVIII, seguido del XIX.

3. Fondo Vicenç Bou, del Museu de la Mediterrània de Torroella de Montgrí (TomB), con 480 manuscritos de autor y 4 anónimos. Repertorio de los siglos XIX y XX.

4. Fondo Josep Pi del Museu de la Mediterrània de Torroella de Montgrí (TomP), con 476 manuscritos de autor, 4 anónimos y 5 impresos. Repertorio de los siglos XIX y XX.

5. Fondo Pere Rigau del Museu de la Mediterrània de Torroella de Montgrí (TomR), con 475 manuscritos de autor y 5 impresos. Repertorio de los siglos XIX y XX.

6. Fondo Capella de Música del Museu-Arxiu de Santa Maria de Mataró (MatC), con 127 manuscritos de autor y 207 anónimos. Repertorio de los siglos XVIII, XIX y XX.

7. Fondo Joan Fargas i Heras del Museu-Arxiu de Santa Maria de Mataró (MatF), con 163 manuscritos de autor, 5 anónimos y 35 impresos. Repertorio de los siglos XIX y XX.

8. Fondo Lluís Viada i Castellà del Museu-Arxiu de Santa Maria de Mataró (MatV), con 131 manuscritos de autor, 27 anónimos y 5 impresos. Repertorio de los siglos XIX y XX.

9. Fondo Ramon Florensa (TagF), procedente de la parroquia de Santa Maria d'Alba, conservado en el Arxiu Comarcal de l'Urgell, con 208 manuscritos de autor y 172 anónimos. Repertorio de los siglos XVIII al XX.

10. Fondo musical de la iglesia parroquial de Sant Esteve d'Olot (SEO), conservado en el Arxiu Comarcal de la Garrotxa (ACGAX), con 1.359 manuscritos de autor, 409 anónimos, 23 libros corales y 468 impresos. Repertorio de los siglos XVIII, XIX y XX.

11. Fondo Teodoro Echegoyen (TEch), conservado en el Arxiu Històric Comarcal de la Garrotxa (ACGAX) con 218 manuscritos de autor, 3 anónimos y 7 impresos. Repertorio de los siglos XIX y XX.

12. Fondo de la basílica de Santa Maria de Castelló d'Empúries (CdE), conservado en el Arxiu Diocesà de Girona, con 209 manuscritos de autor, 96 anónimos y 109 impresos. Repertorio de los siglos XIX y XX.

13. Fondo de la catedral de Tarragona (TarC), conservado en el Arxiu Històric Arxi-Diocesà de Tarragona, con 1.114 manuscritos de autor, 299 
anónimos, 74 libros corales, 5 libros de facistol y 119 impresos. Repertorio de los siglos XVII, XVIII, XIX y XX.

14. Fondo Salvador d'Horta Bofarull (SHB), conservado en la Biblioteca Pública Episcopal del Seminari de Barcelona, con 64 registros (27 manuscritos de autor y 37 impresos). Repertorio de los siglos XVIII, XIX y XX.

15. Fondo de la basílica de Santa María de Igualada (SMI), conservado en el Arxiu Comarcal de l'Anoia (ACAN), con 632 manuscritos de autor, 157 anónimos, 7 libros corales y 188 impresos. Repertorio de los siglos XVIII, XIX y XX.

En el curso de los años 2006, 2007, 2008, 2009 y 2010 la Subdirecció General d'Arxius del Departament de Cultura de la Generalitat de Catalunya subvencionó una parte de la labor del fichaje de los fondos musicales que lidera la cátedra de Patrimonio Musical de la UAB.

A su vez, IFMuC ha contado con cuatro proyectos de investigación del Micinn (2003-2006, 2007-2010, 2011-2014, 2016-2018) para sufragar los costes de infraestructura, equipamiento, dietas y viages para llevar a cabo esta labor inicial.

Bajo el patrocinio de la Subdirecció General de Patrimoni de la Generalitat de Catalunya, hemos iniciado y dirigido la serie "Inventaris de Fons Musicals de Catalunya", dentro de la colección "Eines de recerca. Arxius i documents". El resultado de estos años de investigación aplicada a la recuperación del patrimonio musical catalán ha cristalitzado en la publicación de los volúmenes: (http://publicacions.uab.cat/llibres/titols llibres.asp?TITOL $=$ inventaris + dels + fons + musi $\underline{\text { cals }+ \text { de }+ \text { catalunya\&Submit } 3=\text { Cercar) }}$

1.- Josep Maria Gregori I Cifré. Inventaris dels fons musicals de Catalunya. Volum 1: Fons de la catedral-basilica del Sant Esperit de Terrassa. Barcelona: Departament de Cultura i Mitjans de Comunicació de la Generalitat de Catalunya, 2007. - Arxius i documents. Eines de recerca, 2, (566 p).

2.-Francesc Bonastre i Bertran i Josep Maria Gregori i Cifré, amb la col·laboració d'Andreu Guinart I Verdaguer. Inventaris dels fons musicals de Catalunya. Volums 2/1 - 2/2: Fons de la Parròquia de Sant Pere i Sant Pau de Canet de Mar. Barcelona: Departament de Cultura i Mitjans de Comunicació de la Generalitat de Catalunya, 2009. - Arxius i documents. Eines de recerca, vols. 5/1 - 5/2, (1.014 p).

3.- Marta Grassot i RAdresa. Inventaris dels fons musicals de Catalunya. Volum 3: $\quad$ Fons $V$. Bou, J. Pi i P. Rigan i del Centre Cultural i de la Mediterrania Can Quintana de Torruella de Montgrí. 
IFMUC: UN PROYECTO UNIVERSITARIO PARA LA RECUPERACIÓN DEL

Patrimonio Musical de Catalunya

Barcelona: Departament de Cultura i Mitjans de Comunicació de la Generalitat de Catalunya, 2009. -Arxius i documents. Eines de recerca, 6, (439 p).

4.- Josep Maria Gregori i Cifré I Neus Cabot i SAgrera. Inventaris dels fons musicals de Catalunya. Volum 4: Fons del Museu-Arxiu de Santa Maria de Mataró. Barcelona: UAB Departament de Cultura i Mitjans de Comunicació de la Generalitat de Catalunya, 2010. Arxius i documents. Eines de recerca, 7, (362 p).

5.- Olga NIUBÓ I SALA. Inventaris dels fons musicals de Catalunya. Volum 5: Fons Ramon Florensa de l'Arxin Comarcal de l'Urgell. Barcelona: UAB - Departament de Cultura i Mitjans de Comunicació de la Generalitat de Catalunya, 2011. - Arxius i documents. Eines de recerca, 8, (200 p).

6.- Josep Maria Gregori I CIFRÉ I Carme MONELls I LAQUÉ. Inventaris dels fons musicals de Catalunya. Volum 6: Fons de l'església parroquial de Sant Esteve d'Olot $i$ Fons Teodoro Echegoyen de l'ACGAX. Barcelona: UAB, 2012, (1.218 p).

7.- Josep Maria Gregori i Cifré I Elena SAlgado Cobo. Inventaris dels fons musicals de Catalunya. Volum 7: Fons de la basílica de Santa Maria de Castelló d'Empúries. Barcelona: UAB, 2012, (1.218 p).

8.- Francesc Bonastre i Bertran, Josep Maria Gregori i Cifré, Montserrat Canela i GraU. Inventaris dels fons musicals de Catalunya. Volum 8: Fons de Catedral de Tarragona. Barcelona: UAB, 2015, (865 p).

9.- Josep Maria Gregori i Cifré I Anna Romeu i Solà. Inventaris dels fons musicals de Catalunya. Volum 9: Fons de la basilica de Santa Maria d'Igualada de l'Arxiu Comarcal de l'Anoia. Barcelona: UAB, 2016, (522 p).

La elaboración de los catálogos que hemos realizado durante estos primeros años ha consolidado una metodología para el tratamiento de los fondos musicales, que pronto podrá ser incorporada por la normativa archivística de gestión documental ${ }^{12}$. El sistema de descripción incorpora la digitalización de los íncipits musicales, cosa que permite visualizar las características paleográficas del manuscrito; por otra parte, su agilidad y comodidad de ejecución es incomparable si se piensa en la lentitud que representa informatizar los íncipits musicales o traducirlos a sistemas alfanuméricos.

La confección de cada volumen impreso de la colección IFMuC llega a su término con la redacción de una presentación metodológica, acompañada de un estudio

${ }^{12}$ Con la colaboración de Marta Grassot i Radresa, directora del CEDOC, estamos preparando la confección de una Guia pel tractament $i$ descripció de documents musicals/ Guia para el tratamiento y descripción de documentos musicales. 
introductorio relativo a la personalidad del fondo, su historia y sus principales aportaciones para el conocimiento de la historia de la música en Catalunya. Este estudio introductorio que precede al inventario-catálogo, contiene un capítulo historiográfico elaborado a partir de la documentación conservada en el archivo histórico al que pertenece el fondo, con el objeto de complementar los aspectos históricos de la institución que ha generado la existencia del fondo musical -magisterios de capilla, órgano, escolanes y coplas de ministriles-, así como los perfiles biográficos de los compositores representados en el catálogo, muchos de los cuales han permanecido en el anonimato hasta la edición de los catálogos.

\section{2. OBJETIVOS Y BENEFICIOS}

En el contexto de la gestión del patrimonio musical europeo existe, des hace ya varios años, un creciente interés por la creación de bases de datos con el objetivo de proporcionar el acceso a la información descriptiva de las colecciones de manuscritos musicales conservadas en archivos y bibliotecas. El proyecto IFMuC tiene el objetivo de convertir los fondos de manuscritos musicales en bibliotecas digitales, de forma que todos los ciudadanos puedan acceder con la máxima facilidad a estos grandes volúmenes de conocimiento.

Dentro del ámbito del patrimonio musical catalán existen grades volúmenes de partituras, conservadas de forma manuscrita en numeroso archivos, a menudo con condiciones de acceso poco favorables. De aquí, pues, la urgencia de construir esta plataforma digital con el objetivo de facilitar el libre acceso, en una primera fase, a los registros catalográficos de las colecciones "manuscritos de autor", "manuscritos anónimos", "libros corales" e "impresos" de los fondos catalogados, y, en una fase posterior, al repertorio digitalizado.

Las expectativas de IFMuC se ven colmadas por el hecho sistémico de devolver a la sociedad de nuestro tiempo la inmensa riqueza musical generada en épocas pasadas, conservada en archivos, bibliotecas, museos y centros de documentación musical. Los beneficios del proyecto revierten en diversos ámbitos:

- Científico: mediante la promoción de nuevas investigaciones (trabajos de máster y tesis doctorales) sobre autores y repertorios desconocidos hasta el momento, estilos y épocas de la historia de la música catalana, por parte de la comunidad científica nacional e internacional.

- Artístico: mediante el acceso de los intérpretes nacionales e internacionales a los registros catalográficos de estos repertorios y materiales desconocidos hasta el presente y al libre acceso que tendrán en el futuro a los manuscritos digitalizados.

- Social: toda la sociedad, nacional e internacional, se verá beneficiada por la difusión que intérpretes y gestores musicales podrán efectuar de dichos repertorios a través de sus programaciones de conciertos y grabaciones discográficas. 


\section{IFMUC: UN PROYECTO UNIVERSITARIO PARA LA RECUPERACIÓN DEL Patrimonio Musical de Catalunya}

- Educativo: la enseñanza de la historia de la música podrá incluir en sus trayectos formativos el descubrimiento de antiguos repertorios sonoros desconocidos hasta el presente.

La voluntad del equipo de IFMuC está guiada por el espíritu de restaurar una deuda sistémica, una deuda que vivimos como un deber, no solamente científico, sino también ético y humanístico: el hecho de trabajar con el objetivo de dar a conocer la riqueza de los resultados de un proyecto tan entusiasta como éste, no sólo para los investigadores, intérpretes de música antigua y clásica en general y pedagogos, sino para el conjunto de la sociedad de nuestro tiempo, necesitada como nunca de reencontrar sus raíces y, con ellas, su memoria musical.

\section{CONTENIDOS DE LA PÁGINA WEB http://ifmuc.uab.cat}

La dase de datos consultable desde el web está complementada con la página IFMuC, $<$ Sobre l'IFMuC $>$, en la que junto al texto de presentación se despliegan seis pestañas relativas a:

1. <Arxius, fons i col-lecions > : acceso a los registros catalográficos de las colecciones de los fondos musicales catalogados de los respectivos archivos. El desplegable contiene un listado de los archivos con tres niveles de etiquetas descriptivas per archivo, fondo y cada una de les colecciones del mismo. Cada etiqueta se presenta con un breve texto, acompañado con la ilustración de una imagen perteneciente a la colección. Debajo de la etiqueta de las colecciones se visualizan los respectivos registros catalográficos con los campos de descripción, en formato breve o completo, así como los íncipits musicales digitalizados.

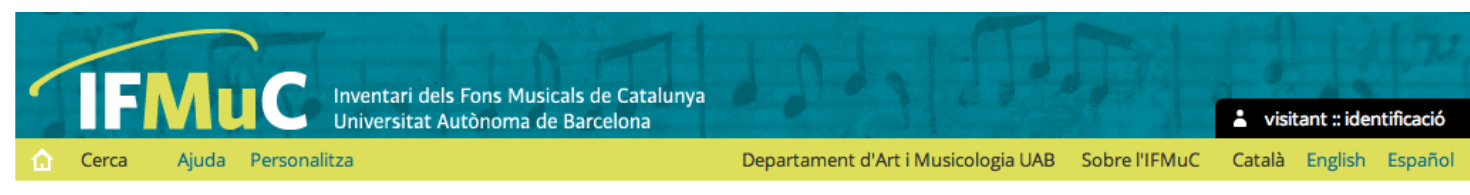

Pàgina inicial > Arxiu Parroquial de Sant Pere i Sant Pau de Canet de Mar > Fons de l'Església Parroquial de Sant Pere i Sant Pau de Canet de Mar (CMar)

Fons de l'Església Parroquial de Sant Pere i Sant Pau de Canet de Mar (CMar)

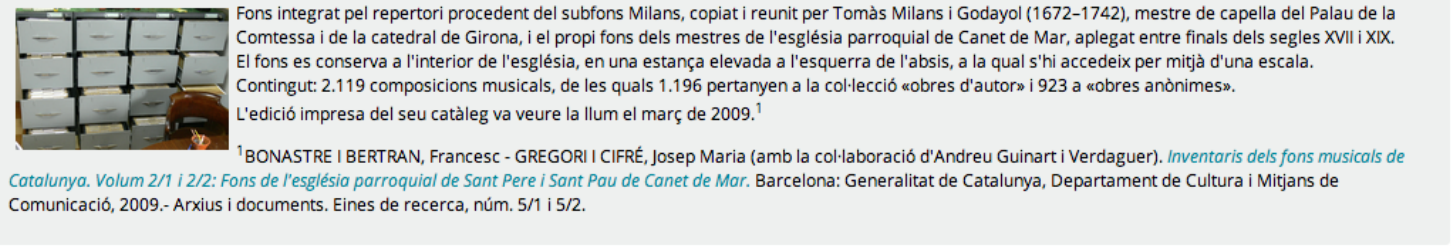

Cercar en 2,119 registres per:

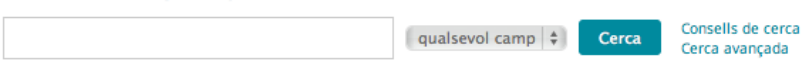

Limitar per col-lecció:

$\searrow$ Fons de l'Església Parroquial de Sant Pere i Sant Pau de Canet de Mar (CMar). Obres d'autor $(1,196)$

$\checkmark$ Fons de l'Església Parroquial de Sant Pere i Sant Pau de Canet de Mar (CMar). Obres anònimes (923)

Fig. 1. 
2. <Fitxa descriptiva dels Fons $>$ : acceso a la ficha descriptiva de cada fondo: Título del fondo - Acrónimo - Enlace con las colecciones - Archivo y localización - Época Volumen y soporte - Productores - Historia archivística - Instrumentos de descripción - Reglas o convenciones - Autoría y fecha - Fuentes - Bibliografía.

3. <Cens Fontes Mvsica Catalonic $>$ : censo de 408 fondos musicales de Catalunya con sus enlaces web. ${ }^{13}$

4. <Estudis sobre Patrimoni>: aceso a los estudios introductorios de los fondos publicados y a trabajos relevantes (TFG, TFM) de los estudiantes de Patrimonio Musical de la UAB.

5. <Bibliografia>: edición de las fuentes bibliográficas relacionadas con los fondos musicales.

6. <Notícies>: difusión de acontecimientos sobre patrimonio musical catalán vinculados o relacionados con el proyecto IFMuC.

\section{BIBLIOGRAFÍA}

Anglés, H. (1935). La música a Catalunya fins al s. XIII. Barcelona: Institut d'Estudis Catalans - Biblioteca de Catalunya.

Bonastre, F. (1976-1977). "La Capella Musical de la Seu de Tarragona a mitjan segle XVIII”. Boletín Arqueológico, ép. IV, fasc. 133-140, pp. 259-270.

Bonastre, F. (1993). "L'Institut de Documentació i d’Investigació Musicològiques Josep Ricart i Matas", en Estudis oferts a Josep Ricart i Matas en la commemoració del centenari del seu naixement (1893-1993). Barcelona: Reial Acadèmia Catlana de Belles Arts de Sant Jordi, pp. 85-91.

Ester-Sala, M. y Vilar, J. M. (1987). "Una aproximació als fons de manuscrits musicals a Catalunya". Anuario Musical, 42, pp. 229-243.

Ester-Sala, M. y Vilar, J. M. (1989). "Una aproximació als fons de manuscrits musicals a Catalunya, II”. Anuario Musical, 44, pp. 155-166.

Ester-Sala, M. y Vilar, J. M. (1991). "Una aproximació als fons de manuscrits musicals a Catalunya, III. Anuario Musical, 46, pp. 295-320.

${ }^{13}$ Véase el listado completo de los fondos en Gregori i Cifré, J. M. (2016). "El Cens IFMuC dels Fons Musicals de Catalunya". Lligall, 38, pp. 136-168.

Cuadernos de Investigación Musical, 2016, diciembre, $\mathrm{n}^{\circ}$ 1, págs. 12-26.

ISSN: 2530-6847 


\section{IFMUC: UN PROYECTO UNIVERSITARIO PARA LA RECUPERACIÓN DEL}

Patrimonio Musical de Catalunya

Ester-Sala, M. y Vilar, J. M. (1992). "Els fons musicals de Catalunya: un patrimoni a revalorar", Lligall, 5.

Gregori i Cifré, J. M. (1977). La producció musical conservada de Joan Crisòstom Ripollès († 1746): catalogació $i$ transcipció (tesis de licenciatura). Barcelona: UAB.

Gregori i Cifré, J. M. (1994). "La catalogació dels arxius musicals de Catalunya, una de les línies de recerca de l'IDIM de la UAB”, en I Congrés de Música a Catalunya. Barcelona: Consell Català de la Música, pp. 863-865.

Gregori i Cifré, J. M. (2008). "El inventario de los fondos musicales eclesiásticos de Catalunya, un proyecto en marcha desde la Universitat Autónoma de Barcelona”. Memoria Ecclesiae, XXXI, pp. 483-497.

Gregori i Cifré, J. M. (2013). "Els Inventaris dels Fons Musicals de Catalunya, el projecte de la UAB per a la recuperació del patrimoni musical", en $2 n$ Congrés Internacional de Música. Barcelona: Consell Català de la Música, pp. 621-625.

Gregori i Cifré, J. M. (2013). "El nou web al servei del patrimoni musical de Catalunya http://ifmuc.uab.cat". Revista Catalana de Musicologia, VIII, pp. 23-35.

Gregori i Cifré, J. M. (2014). "Fondos Musicales en Catalunya: el proyecto IFMuC de la Universitat Autònoma de Barcelona para la recuperación del patrimonio musical catalán”, en M. Nagore y V. Sánchez (eds.). Allegro cum laude. Estudios musicológicos en homenaje a Emilio Casares. Madrid: Instituto Complutense de Ciencias Musicales, pp. 127-134.

Gregori i Cifré, J. M. (2015). “Catalonia project report”. Early Music, 43, pp. 367-368.

Gregori i Cifré, J. M. (2016). "El Cens IFMuC dels fons musicals de Catalunya”. Lligall, 38, pp. 136-168.

Montalt, M. R. (2013). "Cent anys de patrimoni musical a la Biblioteca de Catalunya, 19082008”, en $2 n$ Congrés Internacional de Música. Barcelona: Consell Català de la Música, pp. 626-631.

Pedrell, F. (1891). Por Nuestra Música. Barcelona: Imp. de Henrich y Cª

Pedrell, F. (1894). Hispania Schola Musica Sacra (vol. 3). Barcelona: Juan Bta. Pujol y Ca.

Pedrell, F. (1894-1897). Hispanice Schola Musica Sacra (8 vols.). Barcelona: Juan Bta. Pujol y $\mathrm{C}^{\mathrm{a}}$.

Pedrell, F. (1902-1913). Toma Ludovici Victoria / Abulensis/ Opera Omnia, /ornata a Philippo Pedrell. Leipzig: Ed. Breitkopf und Härtel. Leipzig.

Pedrell, F. (1908). Catàlech de la Biblioteca Musical de la Diputació de Barcelona. Barcelona.

Pedrell, F. (1918-1922). Cancionero Musical Popular Español (4 vols). Valls: Imp. E. Castells. 
Josep MARIA GREGORI I CiFRÉ

Saldoni, B. (1868-1881). Diccionario biográfico-bibliográfico de efemérides de músicos españoles (4 vols.). Madrid: Imp. A. Pérez Dubrull.

Saldoni, B. (1897). Diccionario biográfico y bibliográfico de músicos y escritores de música españoles, portugueses é hispanoamericanos antiguos y modernos, acopio de datos y documentos para servir á la Historia del arte musical en nuestra nación. Barcelona: Tip. de V. Bergós y Feliu.

Fecha de recepción: 13/11/2016

Fecha de aceptación: 15/12/2016 